\title{
Gastric decontamination in aluminium phosphide poisoning: a case against the use of water-based solutions
}

\author{
Hossein Sanaei-Zadeh and Sayed Mahdi Marashi
}

Emergency Room, Division of Medical Toxicology, Hazrat Ali-Asghar (p) Hospital, Shiraz University of Medical

Sciences, Shiraz, Iran

Dear Editor-in-Chief,

We read with great interest the article entitled "A review of aluminium phosphide poisoning and a flowchart to treat it" written by Hashemi-Domeneh et al. (1) and recently published in the Archives of Industrial Hygiene and Toxicology. The authors mentioned performing a gastric lavage using a solution of potassium permanganate $(1 / 10000 / 1 \mathrm{~g}$ per $10 \mathrm{~L})$ and administering activated charcoal ( $1 \mathrm{~g} \mathrm{~kg}^{-1}$ in children and 50-100 $\mathrm{g}$ in adults) and sodium bicarbonate (two 44 meq vials [100 mL] per L) as options for gastrointestinal decontamination, claiming that these compounds can be effective at decreasing toxic phosphine $\left(\mathrm{PH}_{3}\right)$ production. However, a closer look at the list of references in the paper indicated that none of these protocols have yet been clinically studied.

What drew our attention is that these solutions are composed of water. Therefore, they can facilitate $\mathrm{PH}_{3}$ gas release from aluminium phosphide (AlP) (2). To document this phenomenon, we added a $5 \mathrm{~g}$ tablet of Bhostoxin ${ }^{\circledR}$ into $50 \mathrm{~mL}$ solutions of sodium bicarbonate (44 meq), potassium permanganate $(0.005 \mathrm{~g} ; 1 / 10000$ solution), activated charcoal (10 g), and castor oil (see Figure 1).

The other important points recently considered by scientists and which speak in favour of our argument include an exothermic reaction that follows potassium permanganate administration $(3,4)$, induction of haemolysis and methemoglobinemia due to the oxidizing properties of potassium permanganate $(5,6)$, inconceivability of $\mathrm{PH}_{3}$ oxidation following administration of potassium permanganate considering that it is a hard nucleophile (7), and inefficiency of charcoal in AlP adsorption and prevention of $\mathrm{PH}_{3}$ release (8). On the other hand, in vitro studies have proposed that liquid vegetable oils and paraffin are effective in the prevention of phosphine fumigation (9), which has been supported by a successful management of acute AlP poisoning in a case report as well as in an animal study $(10,11)$.

To conclude, solutions composed of water should not be used for gastric decontamination after acute AlP

Correspondence to: Hossein Sanaei-Zadeh, Emergency Room, Division of Medical Toxicology, Hazrat Ali-Asghar (p) Hospital, Meshkinfam Street 7143918796, Shiraz University of Medical Sciences, Shiraz, Iran Email:sanaeizadeh@sums.ac.ir poisoning. Instead, using vegetable oils for gastric lavage or castor oil to inhibit greater $\mathrm{PH}_{3}$ release as well as stimulation of luminal evacuation (2) could be practical. However, this idea has not been evaluated in a properly designed study. Instead of gastric lavage, we have the experience of giving $60 \mathrm{~mL}$ of castor oil orally for gastrointestinal decontamination in all of the cases of acute AlP toxicity presented to the three main university hospitals in Shiraz, Iran, within the last three years. This appears to be a good starting point. Hence, the evaluation of its efficacy in a randomized clinical trial should be the next step.

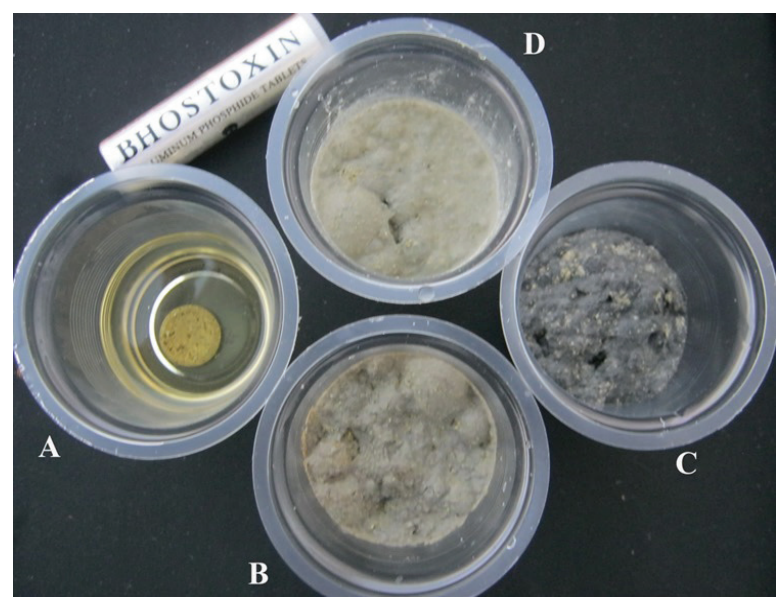

Figure 1 Phosphine gas release from Bhostoxin ${ }^{\circledR}$ tablets in contact with water, regardless of compound. The release of $\mathrm{PH}_{3}$ from the AlP tablets results in the formation of a greenish foamy layer on the surface of the solutions. The formation of $\mathrm{PH}_{3}$ gas bubbles did not occur only in the castor oil container. A: castor oil, B: potassium permanganate solution, $C$ : activated charcoal solution, D: sodium bicarbonate solution

\section{REFERENCES}

1. Hashemi-Domeneh B, Zamani N, Hassanian-Moghaddam H, Rahimi M, Shadnia S, Erfantalab P, et al. A review of aluminium phosphide poisoning and a flowchart to treat it. Arh Hig Rada Toksikol 2016;67:183-93. doi: 10.1515/aiht2016-67-2784

2. Sanaei-Zadeh H. Clinical toxicology for medical students. Unpublished educational booklet, 2015. Shiraz University of Medical Sciences, Shiraz, Iran.

3. Senthilkumaran S, Ananth C, Menezes RG, Thirumalaikolundusubramanian P. Aluminium phosphide 
poisoning: Need for revised treatment guidelines. Indian J Anaesth 2015;59:831-2. doi: 10.4103/0019-5049.171624.

4. Mirakbari SM. Hot charcoal vomitus in aluminum phosphide poisoning - A case report of internal thermal reaction in aluminum phosphide poisoning and review of literature. Indian J Anaesth 2015;59:433-6. doi: 10.4103/00195049.160952.

5. Sanaei-Zadeh H. Response to "blood levels of methemoglobin in patients with aluminum phosphide poisoning and its correlation with patient's outcome". J Med Toxicol 2012;8:86-87. doi: 10.1007/s13181-011-0192-0.

6. Sanaei-Zadeh H. Aluminum phosphide poisoning and development of hemolysis and methemoglobinemia. Indian J Crit Care Med 2012;16:248-249. doi: 10.4103/09725229.106519.

7. Nasri-Nasrabadi Z, Marashi SM. Comments On "A Systematic Review Of Aluminium Phosphide Poisoning".
Arh Hig Rada Toksikol 2012;63: 551. doi: 10.2478/100041254-63-2012-2321

8. Marashi SM, Majidi M, Raji Asadabadi H, Nasri-Nasrabadi Z. A common misconception in the management of aluminum phosphide poisoning. Arh Hig Rada Toksikol 2013;64: 4756. doi: 10.2478/10004-1254-64-2013-2404

9. Goswami M, Bindal M, Sen P, Gupta SK, Avasthi R, Ram BK. Fat and oil inhibit phosphine release from aluminium phosphide-its clinical implication. Indian J Exp Biol 1994;32:647-9. PMID: 7814045

10. Shadnia S, Rahimi M, Pajoumand A, Rasouli MH, Abdollahi M. Successful treatment of acute aluminium phosphide poisoning: possible benefit of coconut oil. Hum Exp Toxicol 2005;24:215-8. PMID: 15957538

11. Saidi H, Shojaie S. Effect of sweet almond oil on survival rate and plasma cholinesterase activity of aluminum phosphide-intoxicated rats. Hum Exp Toxicol 2012;31:51822. doi: $10.1177 / 0960327111407229$ 